\title{
The Influence of Supervisors' Network Position on Postgraduates' Innovative Ability (Based on the Absorptive Capacity of Postgraduates)
}

\author{
Wenping Zhao, Shengnan Zheng \\ School of Economics \& Management, Xidian University, Xi'an, China \\ Email: 243329098@qq.com
}

How to cite this paper: Zhao, W.P. and Zheng, S.N. (2018) The Influence of Supervisors' Network Position on Postgraduates' Innovative Ability (Based on the Absorptive Capacity of Postgraduates). American Journal of Industrial and Business Management, 8, 760-776.

https://doi.org/10.4236/ajibm.2018.83052

Received: March 1, 2018

Accepted: March 27, 2018

Published: March 30, 2018

Copyright $\odot 2018$ by authors and Scientific Research Publishing Inc. This work is licensed under the Creative Commons Attribution International License (CC BY 4.0).

http://creativecommons.org/licenses/by/4.0/

\begin{abstract}
Supervisor is the decisive factor for postgraduates to develop their innovative ability. This paper uses the method of social network analysis to define the concept of the supervisor network position and analyses the intrinsic influence of the supervisor network position, the postgraduates' absorptive capacity and the postgraduates' innovative ability. Absorptive capacity construct the theoretical model among the three as intermediary. The empirical data were collected by questionnaire. The research shows the information as follows: Supervisor's centrality and structure hole have positive influence on postgraduates' innovation ability; the absorptive capacity of postgraduates has a positive effect on the innovation ability of postgraduates, and the absorptive capacity of postgraduates plays a part of mediating role between supervisor network position and postgraduates' innovation ability.
\end{abstract}

\section{Keywords}

Supervisor Centrality, Supervisor Structure Hole, Postgraduate Absorptive Capacity, Postgraduate Innovation Ability

\section{Introduction}

At present, most Universities in China carry out the "one-to-one" supervisor system to cultivate network. Network theory scholars believe that in an intricate cooperative network, each individual is in a different position. The position of the node in the network affects the interaction between the individual and the external environment, and determines the ability of the node to acquire the re- 
sources of knowledge and technology from the network (Koka and Prescott, 2008) [1]. Shenggang and Rui (2014) pointed out that people who occupy a better network position can get a lot of high-quality information and resources [2]. Therefore, supervisors as individuals in a particular collaboration network, occupy a different network position, which affects the access to resources and control.

At the same time, the formation of postgraduates' innovative ability must be affected by specific factors. The individual has some differences in the ability to absorb external knowledge, and it is the difference of these abilities that leads to the difference of individual creativity. From the perspective of dynamic capability, Tao (2007) finds that absorptive capacity has a positive impact on the formation of innovative ability [3]; Andrea and Tribe (2008) pointed out the absorptive capacity of the postgraduate [4]. The supervisor is the main body and the main person in charge of the postgraduate training, which plays a vital role in the cultivation of postgraduates' innovative ability. Scientific research and cooperation are inextricably linked. Under the impetus of an innovative environment, supervisors have begun to cooperate with other supervisors to better access external information and form supervision organizations to enhance innovation capabilities. It can be seen that scholars have made more research on the influence of absorptive capacity on innovation ability, but most of the research objects are concentrated at the organizational level, and the research results of postgraduates are rare. The existing research lacks the theoretical result of the formation of the innovation ability of the postgraduates from the perspective of the supervisor network position. We believe that because the supervisor occupies the different position of the network, the access to information, knowledge, capital and other resources and control ability is different, which directly affects the resources available for postgraduate training, which will inevitably have an impact on the cultivation of postgraduate innovative ability. Therefore, this article focused on the supervisor network position, postgraduate absorptive capacity, and postgraduate innovative ability into a unified theoretical model. It is a useful complement to the existing research, and to provide a new perspective on the formation of innovation ability of postgraduates.

\section{Concept Definition}

\subsection{Supervisor Network Position}

On the network position, researchers give different definitions from different perspectives. That is, the node enterprises in the network's status and power, as well as a more stable relationship between enterprises model. From the perspective of the organization, White (1992) believes the network position represents the enterprise in the cooperative network position [5], From an individual point of view, Tsai (2001) pointed out that there is a complicated relationship between each actor and other actors around in the network, which define the position of the actor in the network [6]; Deming, Siming and Yunsheng (2015) think that 
the network position is the result of the relationship between the actors, and the difference of network position means the chance of getting information stream is different [7].

On the basis of the above theoretical analysis, this paper defines the supervisor network position as: In order to better obtain academic information resources and improve their academic competitiveness, Supervisors establish cooperative relationships with two or more supervisors through academic exchanges and project cooperation, and form a supervisor network. Supervisor in the cooperative network to occupy the node position is the supervisor's network position. At present, the measurement of the position of the network variables, the academic community generally agree with the two dimensions of centrality and structure hole. The measure of centrality is the number of individual nodes is linked in the network with other actors as the standard, reflecting the importance of the individual in the network, the centre of the high degree of node position is located in the core of the network, the edge node of network is located in the centre of the low. A structure hole is a phenomenon in which a node in the network can establish contact with other nodes, but there is a lack of direct contact between other nodes caused by the phenomenon of Interruption. This paper also uses the method of universal division of network position measurement variables in academic circles, divides the supervisor network position into two dimensions: supervisor centrality and supervisor structure hole. The centrality of supervisor is used to measure the degree of centrality of the supervisor in the network and the degree of resource control. Supervisors with high centrality have a certain authority, great visibility and influence in academic circles. They have more opportunities to participate in international academic conferences; and can declare more research projects and research subjects. Supervisor structure hole refers to, if a supervisor linked to the other two supervisors are not directly connected in the network, the supervisor is in the position of the structural hole. The supervisor, who is rich in structural hole position, be able to reach more supervisors of the two sides do not connected, by communicating with these supervisors, you can access different information flows, gain more heterogeneous knowledge, and have the advantage of keeping and controlling information resources.

\subsection{Postgraduate Absorptive Capacity}

The concept of absorptive capacity was first proposed by Cohen and Levinthal, absorptive capacity is the ability of an enterprise to achieve certain results in business through integrating and applying new valuable external knowledge. On this basis, many scholars began to expand the definition of absorptive capacity from different perspectives. From the perspective of organization, Kim believes that absorptive capacity is organizational learning ability and problem-solving skills, and divides it into existing knowledge basic and learning efforts in two dimensions. On the basis of previous studies, for Zahra and George the concept of absorptive capacity has been further improved, putting forward that the ab- 
sorptive capacity is reflected in the dynamic process of enterprise acquisition, digestion, absorption and utilization of knowledge [8]. The current definition of this concept has been widely recognized by academia. Starting from an individual perspective, $\mathrm{Wu}$ and Wang (2008) argue that individual absorptive capacity is embodied in the acquisition, absorption, transformation, application, and re-acquisition of knowledge [9]. Yongqing and Qingpu (2012) say that as the absorption capacity, the individual absorptive capacity refers to the staff inside and outside the enterprise gain valuable knowledge of information through the full digestion and understanding, and ultimately the formation of their own needs to meet the new knowledge of the ability [10].

On the basis of the above theoretical analysis, this paper defines the absorptive capacity of Postgraduates as: transforming external knowledge into knowledge reserves by means of acquisition, digestion, absorption and application, increasing the knowledge stock, optimizing the knowledge structure and applying it to other knowledge of the field of ability.

\subsection{Postgraduate Innovation Ability}

Bums and Stalker first proposed the concept of innovation, he believes that innovation is the ability to successfully adopt or implement new ideas, new technologies and new products. Larry, Rhee and Pursell believes that innovation capability is a comprehensive capacity, covering the information access capacity, organizational skills and technological innovation capabilities. With the deepening of the research on the concept of innovation ability, the research on innovation ability has been gradually involved in various fields. The Organization for Economic Co-operation and Development first extended the concept of "innovation" to the field of education, and innovation in the field of education mainly affects students. After that, more and more scholars realized the importance of University Postgraduates innovative ability for national innovation and development, and began to explore the innovative ability of Postgraduate students from different angles. From the point of view of the psychological characteristics of Postgraduate students, Chunmei and Qiaojuan (2004) pointed out that the innovation ability mainly refers to the creative consciousness, the pioneering thinking and the exploration spirit, and can use the knowledge creatively to solve the problem. From the perspective of the comprehensive ability of Postgraduate students [11], Zefang and Qing (2013) pointed out that the innovation ability of postgraduate students is based on the existing knowledge reserves, make full use of internal and external conditions, creatively discover problems, ask questions, analyze problems and solve problems [12].

On the basis of the above theoretical analysis, this paper defines the innovation ability of postgraduate students as follows: The individual has accumulated knowledge, experience and methods on the basis of its own knowledge stock, through scientific thinking processing and reconstruction, with new ideas, new methods and new results displayed a kind of comprehensive ability. The specific 
performance is innovative resources utilization ability, innovative thinking promotion ability, innovation achievement output ability and so on.

\section{The Theoretical Model and Research Hypotheses}

In China, the supervisor's guidance to postgraduate students is mostly through teaching, scientific research activities and so on to achieve. Supervisor through the comprehensive use of their own training resources, they can play a full range of guiding role in guiding the all-round development of postgraduate students. Therefore, based on the theory of network position, this paper puts forward that the social network relationship, scientific research ability and knowledge information of supervisors will have a great influence on the cultivation of postgraduate students' knowledge and creative thinking, that is, the difference of Supervisors' Network Position will produce differentiated impact on postgraduate absorptive capacity and postgraduate innovation ability.

\subsection{Supervisor Network Position and Postgraduate Absorptive Capacity}

\section{1) Supervisor centrality and postgraduate absorptive capacity}

Supervisors with high centrality have strong strength and competitiveness in academic circles. They can use a variety of channels to declare more research projects and research. In the process of participating in the research project and the research of the supervisors through the means of communication and interaction, the supervisors can impart methods, experience and skills of the scientific research to the postgraduate students, which enable them to acquire new knowledge, improve the stock of knowledge (Shuijing and Yao, 2016) [13]. And the amount of knowledge reserves will affect the absorptive capacity of the subject (Zhoutao and Jiaying, 2015) Accordingly [14], we believe that the centre of the high teacher can allow postgraduate students to participate in more research projects and research, for students to create a good research environment, through a wide range of scientific research between teachers and students to exchange interaction to stimulate students to explore knowledge. The desire to constantly increase the knowledge of the stock, enhance the absorption capacity. Therefore, the following assumption is made in this paper:

H1a: Supervisor centrality has a positive impact on the absorptive capacity of postgraduate students

\section{2) Supervisor structure hole and postgraduate absorptive capacity}

The supervisor who occupies the rich structure hole position can bring together a lot of non-redundant knowledge information, and transfer the heterogeneous knowledge information to the postgraduate students in the teaching research. The greater the heterogeneity of knowledge, the more knowledge of the subject's contact, the greater the scope of knowledge is involved, the stronger the motivation of the subject to improve its absorptive capacity, and the ability to absorb it (Suzhen and Rui, 2011) [15]. According to this, we believe that occu- 
pying a rich structure of the position of the supervisor, to provide a rich type of knowledge for postgraduate students to stimulate the enthusiasm to absorb new knowledge, improve the efficiency of knowledge absorption. Therefore, the following assumption is made in this paper:

H1b: The supervisor occupies a rich structural hole position has a positive effect on the absorptive capacity of postgraduates

\subsection{Postgraduate Absorptive Capacity and Postgraduate Innovative Ability}

Pennings and Harianto argue that innovation is a complex activity, and the ability to absorb and use external knowledge is an important prerequisite for innovation. Fosfuri and Tribó (2008) proposed that absorptive capacity plays an important role in the transformation of external knowledge into innovative performance [16]. The domestic scholars Fuhu and Xicang also made an empirical study on the relationship between absorptive capacity and innovation. The conclusion shows that there is a positive correlation between absorptive capacity and innovation [17]. Accordingly, we believe that the strong absorptive capacity of postgraduates to constantly adjust and update the knowledge structure, thinking mode has greater flexibility, to a new perspective to explore things, so as to continuously improve their ability to innovate. Therefore, the following assumption is made in this paper:

H2: Postgraduate absorptive capacity has a positive impact on innovative ability of postgraduates

\subsection{Supervisor Network Position and Postgraduate Innovation Ability}

\section{1) Supervisor Centrality and postgraduate innovation ability}

The Supervisors with high centrality have certain authority in academic circles, can regularly participate in international academic conferences, and understand the new direction of academic research and development. In the course of teaching research for postgraduates, we can make them contact with the development of frontier of the academic field, understand the trend of science and technology development, expand the knowledge view, improve their knowledge of driving ability, grasp the law of future change, so as to stimulate innovation consciousness, improve innovation ability (Ma, 2010) [18]. Domestic scholars such as Kai and Jie (2015) think that in the most advanced research field supervisors can help students better understand the academic frontier and the development direction in this field, to stimulate their desire for learning knowledge of uncertainty, to guide students to put forward problems with foresight and creativity, inspire innovative thinking, and enhance the innovation capability [19]. Accordingly, we believe that supervisors with a high degree of centrality can deliver cutting-edge information to postgraduates, stimulate curiosity and innovative thinking of postgraduates, and improve their creativity. Therefore, the following assumption is made in this paper: 
H3a: Supervisor Centrality has a positive impact on postgraduates' ability to innovate

2) Supervisor structure hole and postgraduate innovation ability

The acquisition of heterogeneous knowledge means the diversity of available knowledge, skills and specialties. It can broaden individual knowledge and stimulate creative thinking. It is an important resource for developing creativity. For Rodan and Galunic (2004) C's study found that knowledge heterogeneity is positively related to team innovation [20]. The study of $\mathrm{Gu}$ and $\mathrm{Hu}$ also found that knowledge heterogeneity had a positive effect on innovation. On the basis of the existing literature research, this paper argues that the supervisor who occupies the rich structural hole position will transmit the heterogeneity knowledge to the postgraduates, can provide more areas of knowledge and ideas for them, they will stimulate different areas of knowledge, views and opinions for effective integration, and thus produce more creative achievements. Therefore, the following assumption is made in this paper:

H3b: Supervisors who occupy rich structural holes have a positive impact on postgraduates' ability to innovate

\subsection{The Mediating Role of Postgraduates Absorptive Capacity}

With the gradual development of absorptive capacity, the relevant research in this field is becoming more and more mature. With regard to the intermediary role of absorptive capacity and its impact on innovation, more and more scholars began to study from the relevant perspective of social networks, From the perspective of the characteristics of collaborative innovation network, Xuemei and Leilei (2013) pointed out that the knowledge absorptive capacity is part of the mediating effect between collaborative innovation network (network size, network homogeneity, network strength and enterprise innovation performance [21]. From the perspective of network connection, Lei and Qiaozhen (2014) considered in the process that the influence of network connections on the innovation performance of cluster enterprises, absorptive capacity plays an intermediary role [22]; from the relations strength of network, Xueyuan and Jingwen (2016) pointed out that the absorptive capacity of enterprises play a partial mediating role between network intensity and enterprise innovation performance [23]. Therefore, on the basis of scholars' research, this paper puts forward that the absorptive capacity of postgraduates plays an intermediary role in the process of the impact of the tutor network position on the postgraduates' innovative ability.

1) The intermediary ability of postgraduate absorptive capacity between supervisor centrality and postgraduate innovation ability

Supervisors with high centrality are at the forefront of the academic field, and are more likely to guide students to value learning and innovation. Therefore, through the scientific research projects and research topics, the supervisors imparting academic frontier information to students, to stimulate graduate stu- 
dents strong learning motivation and open up new areas of knowledge willing, to a certain role in promoting their knowledge acquisition, digestion, absorption and application, is conducive to improving the absorptive capacity of postgraduates. Good absorptive capacity enables postgraduates to apply their acquired information and knowledge to innovative activities, thereby enhancing their creativity. Therefore, the following assumption is made in this paper:

H4a: The absorptive capacity of postgraduates plays an intermediary role between supervisor centrality and postgraduate innovative ability

2) The mediating role of postgraduate absorptive capacity between the supervisor's structural holes and the postgraduates innovative ability

The supervisor, who occupies the rich structure hole position, holds a lot of non-redundant knowledge information. He paid more attention to the continuous improvement of the knowledge structure of postgraduates, the cultivation of cross-thinking and the output of innovation achievement. When postgraduates through a variety of channels to acquire heterogeneity knowledge from supervisor, these heterogeneity knowledge may be involved in knowledge digestion, absorption and application, because the inflow of these knowledge will bring new perspectives and opportunities for postgraduates, will stimulate the absorbing ability. Knowledge-strong graduate students have not only increased their knowledge stock by strong identification and access to external heterogeneity knowledge, but also the integration of old and new knowledge systems is more creative and inspiring to improve the potential of innovation. Therefore, the following assumption is made in this paper:

H4b: The absorptive capacity of postgraduates plays an intermediary role between Supervisor structural holes and postgraduate innovative ability

In summary, the supervisor network position effect on innovation ability of postgraduates-based on the mediating role of absorptive capacity of postgraduates. In this paper, there are four potential variables included such as: supervisor centrality, supervisor structure hole, postgraduate absorptive capacity and postgraduate innovation ability. Supervisor network position, postgraduate absorptive capacity and postgraduate innovation capacity of the structural model assumptions shown in Figure 1:

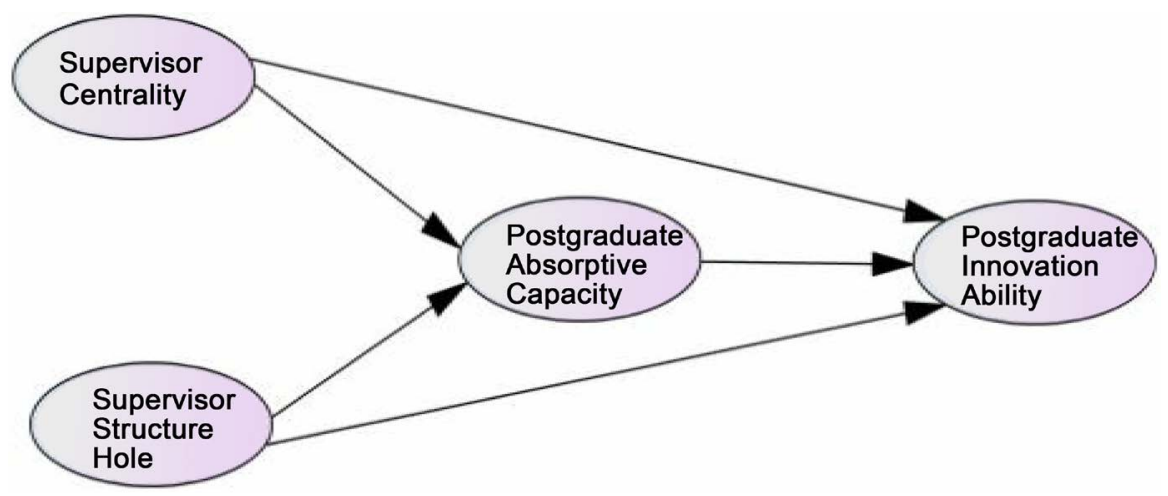

Figure 1. Structural model hypothesis of supervisor network position, postgraduate's absorptive capacity and postgraduate's Innovative Ability. 


\section{Research Design}

\subsection{Questionnaire Design and Distribution}

On the basis of the existing research, this paper summarizes the relevant literatures about the position of the supervisor, the absorptive capacity of postgraduates and the innovative ability of postgraduates, and compiled the questionnaire. The questionnaire consists of five parts: the first part is the basic information of postgraduates, including gender, age, graduate class and professional; the second part is the basic information of postgraduate supervisor, including gender, age, the time and title of postgraduate supervisor, and the number of the current postgraduates; the third part is the measurement of the position of the supervisor network, including two dimensions: the supervisor centrality and the supervisor structure hole; the fourth and fifth parts are the absorptive capacity of postgraduates and the innovation ability of postgraduates, the data of this study are based on the questionnaire survey of postgraduates in Xi'an. The survey selected to XiDian University, Northwestern Polytechnical University, Xi'an Jiao Tong University and other colleges and universities in Xi'an postgraduates questionnaire to collect data, by way of field visits questionnaires, effectively ensure the reliability of the survey results. The survey was conducted between October and November of 2016. A total of 362 questionnaires were issued and 330 questionnaires were recovered. Among them, 285 were valid questionnaires and the effective rate was $86.3 \%$.

\subsection{Variable Measurement}

The questionnaire of this paper fully refers to the relevant research results of scholars at home and abroad, and makes a strict reliability and validity test. Questionnaire topics are used in the form of LIKERT five-point scale, from 1 - 5 representatives from completely disagree to fully agree. In the measurement of supervisor network position, according to Leinetal (2004), Fuetal (2006) and Mehraetal (2011) on the network position of the scale, combined with the particularity of the supervisor's network position. This paper has developed a two dimension supervisor network position scale with 5 items. As for the supervisor centrality, the following 3 indicators are used to measure: My supervisor has a deep academic attainments and has high reputation in academic circles; my supervisor published scientific research papers with a high level, there are many papers published in the core academic journals at home and abroad, and have been cited many times; my supervisor can declare more scientific research subjects, such as the Ministry of Science and Technology projects, the National Natural Science Fund Project, the National Social Science Fund projects. The supervisor structure hole is mainly used the following two items to measure: my supervisor often collaborates with other supervisors to match the matchmaking; my supervisor can always communicate directly with other supervisors, rather than relying on third parties to pass information.

As for absorptive capacity, there are more mature scales both at home and 
abroad: Liao, Welsch and Stoica (2003) developed two dimensions of the 12-item Absorptive Capacity Scale; Devinney and Midgley (2004) developed 6 items of individual absorptive capacity scale; Xiaobing and Shenghua (2006) developed 4 dimensions and 12 items of the absorptive capacity scale; For the measurement of absorptive capacity, many scales in the academic field are measured by multi-dimensional division. However, this paper aims to study the absorption capacity as a whole variable. Therefore, according to Xiaojun the knowledge absorptive ability of postgraduates, appropriate deletion, to make it more in line with the research background of this paper. Mainly from the postgraduate knowledge acquisition, digestion, absorption and application of four aspects of measurement, a total of five items. In the aspect of postgraduate innovation ability scale, this paper, based on the reference of Fuxia (2007) postgraduate' innovation ability scale [24]. From the graduate students with ideas open, agile, flexible features, new ideas, new ideas continue to emerge; have the flexibility to break the fixed mode of thinking, to multi-directional thinking; like to put forward a different view and deal with the problem in a novel way; with the ability to explore and develop new areas, and published a high level of papers and other 5 indicators to measure them.

\section{Empirical Analysis}

In this study, the structural equation model is used to analyse the 285 samples collected, and to test the 7 hypotheses.

\subsection{Reliability and Validity Test}

The reliability test is measured by the Cronbach's alpha coefficient, as shown in Table 1:

The Cronbach's alpha values of this study variables were all greater than 0.7, indicating that the measurement scale had better internal consistency.

The questionnaire used in this paper is based on the mature questionnaires of scholars at home and abroad, and the relevant literatures as the theoretical basis,

Table 1. Reliability test.

\begin{tabular}{ccc}
\hline variable & Items & Cronbach's Alpha \\
\hline $\begin{array}{c}\text { Supervisor } \\
\text { Centrality }\end{array}$ & 3 & 0.895 \\
$\begin{array}{c}\text { Supervisor } \\
\text { Structure } \\
\text { Hole }\end{array}$ & 2 & 0.796 \\
$\begin{array}{c}\text { Postgraduate } \\
\text { Absorptive } \\
\text { Capacity }\end{array}$ & 5 & \\
$\begin{array}{c}\text { Postgraduate } \\
\text { Innovation } \\
\text { Ability }\end{array}$ & 5 & 0.842 \\
& & \\
& 5 & 0.909
\end{tabular}


through consult the experts and carefully revised, finally determine the suitable questionnaire for this study, therefore, the questionnaire has good content validity in the content. At the same time, Amos was used to test the construct validity of the scale, the index shown in Table 2:

\subsection{Structural Equation Path Model Test}

According to the relationship between the three variables assumes that the network position of supervisor, the absorptive capacity of postgraduates and the innovation ability of postgraduates. In this paper, the absorptive capacity of postgraduates as the intermediary, supervisor centrality and supervisor structure hole as the exogenous latent variable, postgraduates "absorptive capacity and postgraduates" innovative ability as the endogenous latent variable. Finally, constructs the path model and carries on the model test, the test results are shown in Figure 2:

Supervisor network position, postgraduates' absorptive capacity and postgraduates' innovative ability model test results show that. The factor load of each item is more than 0.6, and from the Table 2 model fitness index value shows that the model of the various indicators meet the standard, indicating that the model is ideal, can be carried out hypothesis test.

\subsection{Analysis of Causal Path between Variables}

Figure 2 shows that the supervisor network position, postgraduate absorptive

Table 2. Fitness index value.

\begin{tabular}{cccccc}
\hline GFI & AGFI & RMSEA & $\chi^{2} / \mathrm{df}$ & TLI & IFI \\
\hline 0.931 & 0.962 & 0.068 & 0.826 & 0.960 & 0.975 \\
\hline
\end{tabular}

Noted: GFI $=0.931>0.9$, AGFI $=0.962>0.9$, RMSEA $=0.068<0.08, \chi^{2} / \mathrm{df}=0.826<2, \mathrm{TLI}=0.960>0.9$, IFI $=0.975>0.9$ indicating that the measurement scale has a good validity, the project design is reasonable.

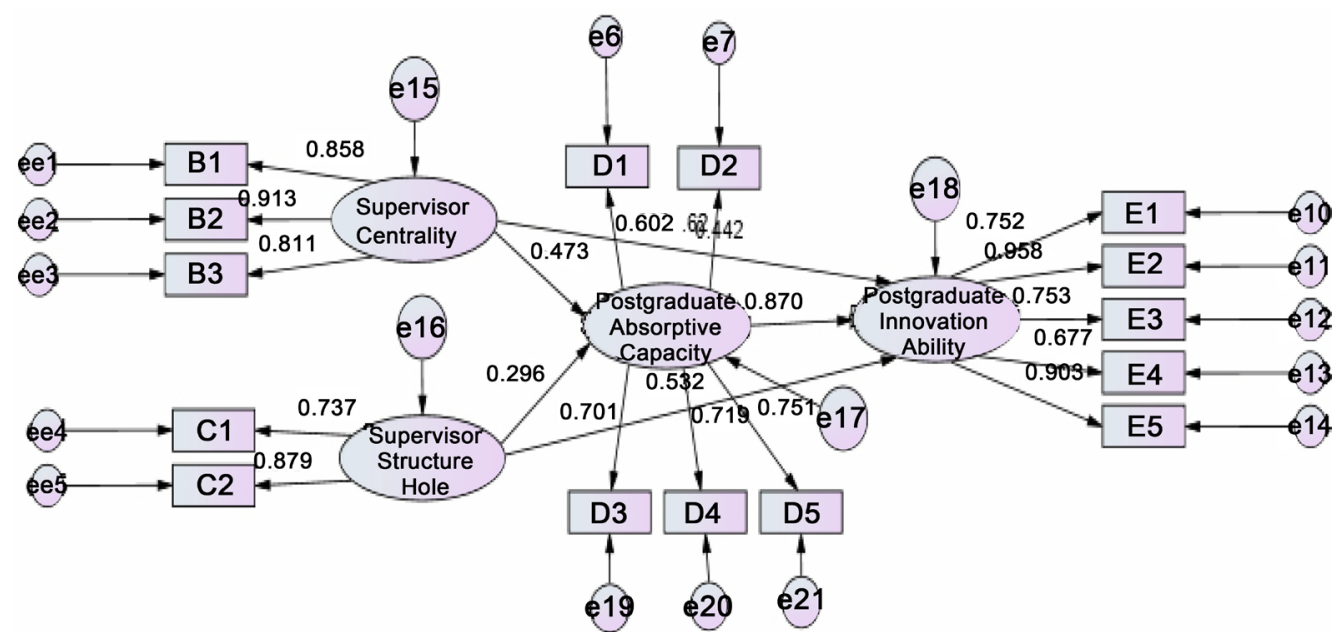

Figure 2. Supervisor network position, postgraduate's absorptive capacity and postgraduate's innovation ability model. 
Table 3. Model path coefficient estimation of supervisor network position, postgraduate absorptive capacity and postgraduate innovative ability.

\begin{tabular}{lcccc}
\hline \multicolumn{1}{c}{ Variable path } & $\begin{array}{c}\text { Standard } \\
\text { estimate }\end{array}$ & $\mathbf{P}$ & $\begin{array}{c}\text { Corresponding } \\
\text { hypothesis }\end{array}$ & $\begin{array}{c}\text { Validation } \\
\text { results }\end{array}$ \\
\hline $\begin{array}{l}\text { Supervisor Centrality } \rightarrow \\
\text { Postgraduate Absorptive Capacity }\end{array}$ & 0.473 & $0.006^{* *}$ & H1a & support \\
$\begin{array}{l}\text { supervisor structure hole } \rightarrow \\
\text { Postgraduate Absorptive Capacity }\end{array}$ & 0.296 & $0.025^{*}$ & H1b & support \\
$\begin{array}{l}\text { Supervisor Centrality } \rightarrow \\
\text { Postgraduate Innovation Ability }\end{array}$ & 0.442 & $0.007^{* *}$ & H3a & support \\
$\begin{array}{l}\text { supervisor structure hole } \rightarrow \\
\text { Postgraduate Innovation Ability }\end{array}$ & 0.532 & $* * *$ & H3b & support \\
$\begin{array}{l}\text { Postgraduate Absorptive Capacity } \rightarrow \\
\text { Postgraduate Innovation Ability }\end{array}$ & 0.870 & $* * *$ & $\mathrm{H} 2$ & support \\
\hline
\end{tabular}

Note: ${ }^{* *}$ stands for less than 0.001 significant; ${ }^{* *}$ stands for less than 0.01 significant; ${ }^{*}$ stands for less than 0.05 significant.

capacity and postgraduate innovation model parameters are estimated through the test. The test results show that (as shown in Table 3), Supervisor centrality, supervisor structure hole and the postgraduate absorptive capacity of the standard path values were 0.473 and 0.296 , and the $P$ value shows that the path passes the significance test, thus supporting the hypothesis of this study H1a and H1b; the standardized path values of the supervisor centrality, supervisor structure hole and postgraduate innovation ability are 0.442 and 0.532 , and the P value shows that the path passes the significance test, which supports the hypothesis of $\mathrm{H} 3 \mathrm{a}$ and $\mathrm{H} 3 \mathrm{~b}$ in this study. The standardized path value of postgraduates' absorptive capacity and postgraduates' innovation ability was 0.870 , and the $\mathrm{P}$ value showed that the path was tested by significance test, which supported the hypothesis of $\mathrm{H} 2$.

Supervisor Centrality $\rightarrow$ Postgraduate Absorptive Capacity

From the above inspection instructions, the supervisor centrality is positively related to postgraduates' absorptive capacity and postgraduates' innovative ability. There is a significant positive correlation between supervisor structure and postgraduate absorptive capacity and postgraduate innovation ability. There is a significant positive correlation between postgraduate absorptive capacity and postgraduate innovation ability.

\subsection{Intermediary Hypothesis Test}

As for the intermediary effect test, this paper adopts the intermediary test method put forward by Mackinnon (2009): Test the independent variable to the intermediary variable (parameter is a); the mediator variable to the dependent variable test (the parameter is $b$ ), and verify the hypothesis $\mathrm{H} 0$ : If $a b=0$, the mediator $\mathrm{M}$ does not exist; if $\mathrm{ab} \neq 0$, then $\mathrm{M}$ is the mediator variable of $\mathrm{X}$ and $\mathrm{Y}$ [25]. Based on the above method, we have verified that $\mathrm{H} 0$ is not established. Therefore, this study supports the hypothesis that H4: postgraduates' absorptive 
capacity plays a mediating role between supervisor centrality and postgraduate innovation ability; H5: Postgraduate absorptive capacity plays an intermediary role between the innovation ability of postgraduates and supervisor structural holes.

In order to further study the influence relationship between variables, this study decomposes the variable relation effect into direct effect and indirect effect. In this paper, based on the model test drawn the Supervisor Centrality, Supervisor Structure Hole, postgraduate absorptive capacity and postgraduate innovation ability. In this paper, based on the model test to draw a direct effect and indirect effects of standardized coefficient table about supervisor centrality, supervisor structure Hole, postgraduate absorptive capacity and postgraduate innovation ability (as shown in Table 4):

The mediating effect analysis showed that: if the ratio between the indirect effect and the direct effect is greater than 1 , then the intermediate variable existing between the two variables plays a role of complete mediation. On the contrary, if the indirect effect between the two variables and the direct effect of the ratio of less than 1, the two variables exist intermediary plays a partial mediating role. Table 4 shows that the ratio of indirect effect and direct effect of supervisor centrality on postgraduate innovation ability is $0.473 \times 0.870 / 0.442=0.930<1$, The direct effect is greater than the indirect effect, which shows that the absorptive capacity of postgraduates plays a partial mediating role in the impact of supervisor centrality on postgraduates' innovative ability, thus further verifying the hypothesis $\mathrm{H} 4$; the ratio of the indirect effect and the direct effect of the supervisor structure hole on the postgraduates' innovation ability is

$$
0.296 \times 0.870 / 0.8532=0.485<1
$$

The direct effect is also greater than the indirect effect, indicating that the absorptive capacity of postgraduates also play a part of intermediary role between the impact of supervisor structure hole and postgraduate innovation ability, which further validates the hypothesis of this study $\mathrm{H} 5$.

\section{Conclusion and Inspiration}

This paper analyses the influence of supervisor network position on postgraduates' innovation ability. The mediating role of postgraduates' absorptive capacity

Table 4. Summary of relational effects of model variables.

\begin{tabular}{lccc}
\hline \multicolumn{1}{c}{ Variable path } & Direct & $\begin{array}{c}\text { Indirect } \\
\text { effect }\end{array}$ & $\begin{array}{c}\text { Total } \\
\text { effect }\end{array}$ \\
\hline effect & 0.442 & 0.411 & 0.853 \\
Supervisor Centrality $\rightarrow$ Postgraduate Innovation Ability & 0.532 & 0.258 & 0.790 \\
supervisor structure hole $\rightarrow$ Postgraduate Innovation Ability & 0.473 & 0.473 \\
Supervisor Centrality $\rightarrow$ Postgraduate Absorptive Capacity & 0.296 & 0.296 \\
supervisor structure hole $\rightarrow$ Postgraduate Absorptive Capacity & 0.870 & 0.870 \\
Postgraduate Absorptive Capacity $\rightarrow$ Postgraduate Innovation Ability & & &
\end{tabular}


was discussed and the empirical test was completed by collecting the data from the questionnaire. The following conclusions are drawn from the study: Supervisor network position (supervisor centrality, supervisor structure hole) can significantly affect the postgraduates' innovative ability. The higher the supervisor's central position in the cooperation network and the more structural holes, the greater the advantage of obtaining information resources. And then, in the process of guiding postgraduates, the introduction of their leading academic information and diverse information is beneficial to stimulate their innovative thinking and enhance their creative ability; the center position of postgraduate tutor and graduate student absorptive capacity have a positive effect on the innovation ability of postgraduate students; the tutor structure hole plays an intermediary role in the innovation ability of graduate students. The supervisor passes the information obtained by the centrality of the network position and the structure hole to the postgraduates. Rich postgraduates' knowledge, broadens their academic horizons, and enhances their ability to innovate, and postgraduates' own absorptive capacity plays a connecting role. The stronger the absorptive capacity of graduate students, the greater the ability to acquire, digest, absorb, and apply external information, and can continue to internalize external knowledge into their own knowledge reserves and increase knowledge stock. A rich knowledge stock can stimulate divergent thinking of postgraduates, explore the essence of things, put forward new ideas and explore new fields of knowledge.

The conclusions of this paper give us the following inspiration: Postgraduates should constantly improve their absorptive capacity, and then promote the upgrading of innovative ability. First of all, postgraduates should actively participate in the supervisor's research projects, research, through a variety of academic exchanges to obtain a variety of external knowledge, experience and methods, to provide a favourable source of information for future innovation. Secondly, in order to better absorb the useful information and transform it into innovative output, we should try our best to improve our professional knowledge and understand the relative theories of our own subject areas. Finally, we should continue to increase our knowledge in interdisciplinary fields, strengthen our own knowledge structure, and lay the foundation for the collision of knowledge in different fields. Because the supervisor's network position has a positive impact on the innovative ability of postgraduates, it is possible to improve the innovative ability of postgraduates by enhancing the network position of supervisors. On the supervisor centrality, the supervisor should strive to enhance their influence in academia, declare more scientific research projects and topics and allow graduate students to participate in, so that postgraduates understand the latest developments in the field, always maintain the forefront of the sensitivity, and then bring forth new ideas and produce innovative results. On the supervisor structure hole, the supervisor should actively participate in domestic and international academic exchange activities, and constantly improve the ability of in- 
ternational communication, expand social communication network, contact more teachers in different areas, for the cooperation between the supervisors from the role of matchmaking. And the heterogeneity of knowledge will be transferred to postgraduates, and the heterogeneous knowledge will provide opportunities for creative sparks collision, excitation, cross and integration in the mind, and thus promote the improvement of postgraduates innovation ability. In order to promote the innovation ability of postgraduates, institutions of higher education and other educational institutions also need to take measures to provide a good soft environment for the network position of supervisors and the promotion of postgraduates' absorptive capacity. First of all, the university should be as much as possible to improve international communication channels, Regularly arrange supervisors to foreign well-known universities and academic level in the international forefront of the top professional high-level training, and strive to improve the depth and breadth of their research in the field, Expand its visibility and influence in the field, so as to continuously improve the supervisor centrality; Second, colleges and universities should increase their investment in academic exchanges, encourage and support supervisors to undertake academic exchange meetings independently, and invite supervisors from different academic fields to attend meetings, so that they can reach more non-redundant contacts and expand the scope of social communication, Lay the foundation for enriching the number of supervisor structure hole. Finally, colleges and universities should embody the frontier and comprehensiveness in setting up postgraduates courses. So that postgraduates in laying a solid professional foundation, to build a reasonable knowledge structure at the same time, to be able to learn advanced knowledge and research methods of related disciplines, so as to continuously improve their absorptive capacity and innovation.

\section{References}

[1] Koka, B.R. and Prescott, J.E. (2008) Designing Alliance Networks: The Influence of Network Position, Environmental Change, and Strategy on Firm Performance. Strategic Management Journal, 29, 639-661. https://doi.org/10.1002/smj.679

[2] Ren, S.G., et al. (2014) Entrepreneur Network Capacity and Entrepreneurial Opportunities: The Mechanism of Network Position and Network Span. Nankai Management Review, 1, 123-133.

[3] Tao, Z. (2007) Research on the Relationship between Innovation Ability and Competitive Advantage Based on Absorptive Capacity. Science Research, 27, 445-452.

[4] Andrea, F. and Tribe, J.A. (2008) Exploring the Antecedents of Potential Absorptive Capacity and Its Impact on Innovation Performance. The International Journal of Management Science, No. 36, 173-187.

[5] White, H. (1992) Identity and Control: A Structural Theory of Social Action. Princeton University Press, Princeton, 84-92.

[6] Tsai (2001) Knowledge Transfer in Intraorganizational Networks: Effects of Network Position and Absorptive Capacity on Business Unit Innovation and Performance. Academy of Management Journal, 44, 996-1004.

[7] Deming, Z., Siming, Z. and Yunsheng, Z. (2015) Research on the Influence of Net- 
work Position, Technology Diversification and Enterprise in Technical Standard Setting. Journal of Management, 2, 198-206.

[8] Zahra, S.A. and George, G. (2002) Benefiting from Network Position: Firm Capabilities Structural Holes and Performance. Strategic Management Journal, 26, 809-825. https://doi.org/10.1002/smj.482

[9] Wu, P. and Wang, Y. (2008) Research of Personal Absorptive Capacity of Knowledge Based on Communities of Practice. Computer Science and Software Engineering International Conference, No. 12, 137-140.

[10] He, Y.Q. (2012) Connotation and Structure Dimensions of Knowledge Absorptive Capacity: Based on Human Digestion and Absorption Perspective. Information Theory and Practice, 3, 32-36.

[11] Yang, C.M. (2004) Curriculum and Teaching: the Basis of Cultivating Innovative Ability of Postgraduates. Research on Higher Education in Heilongjiang Province, No. 6, 119-121.

[12] Dong, Z.F. (2013) Investigation and Analysis of Graduate Students' Innovative Ability in China. Degree and Graduate Education, 2, 1-5.

[13] Xue, S.J. (2016) Research on the Relationship between Supervisors and Postgraduates in Chinese Postgraduate Education. Modern University Education, No. 5, 80-87.

[14] Cao, Z.T. (2015) A Study on the Cooperative Path of Knowledge Heterogeneity Promoting Knowledge Innovation, Science and Technology Progress and Countermeasures, No. 17, 134-138.

[15] Zheng, S.Z. (2011) Knowledge Heterogeneity, Absorptive Capacity and Evolution of Cluster Life Cycle. Science and Technology Management Research, No. 13, 154-158.

[16] Fosfuri, A. and Tribó, J.A. (2008) Exploring the Antecedents of Potential Absorptive Capacity and Its Impaction Innovation Performance. The International Journal of Management Science, 36, 173-187.

[17] Wang, F.H. (2014) A Study on the Relationship between Knowledge Acquisition, Absorptive Capacity and Enterprise Innovation. Science and Technology Progress and Countermeasures, No. 6, 130-134.

[18] Ma, Z. (2010) Cultivation of Students' Scientific and Technological Ability for Innovation. Asian Social Science, 6, 76-80.

[19] Kai, X. and Jie, X. (2015) Examining and Thinking on Three Obstacles Facing the Cultivation of Graduate Students' Innovative Ability. Graduate Education Research, No. 6, 46-49.

[20] Rodan, R. and Galunic, C. (2004) More than Network Structure: How Knowledge Heterogeneity Influences Managerial Performance and Innovation. Strategic Management Journal, 25, 541-562.

[21] Xie, X.M. (2013) Enterprise Collaborative Innovation Network Features and Innovative Performance: A Study of Mediating Effects Based on Knowledge Absorptive Capability. Nankai Management Review, No. 3, 47-56.

[22] Wang, L. (2014) The Relationship between Local Network Connection and Global Network Connection and Cluster Enterprise Innovation Performance-Mediating Role of Absorptive Capacity. Technology Economy, No. 8, 1-9.

[23] Liu, X.Y. (2016) Research on the Relationship among Relationship Strength, Absorptive Capacity and Innovation Performance in Enterprise Innovation Network. Nankai Management Review, No. 1, 30-42.

[24] Guo, F.X. (2007) Graduate Students Innovation Capacity Status and Training Re- 
search in Chongqing University. Chongqing University, Chongqing.

[25] Mackinnon (2009) Current Directions in Mediation Analysis. Current Directions in Psychological Science, 18, 16. 